\title{
Panorama das Políticas Públicas voltadas para questões socioambientais implantadas por Secretarias Municipais de Meio Ambiente da região Sudeste do Pará
}

\author{
Overview of Public Policies focused on socio-environmental issues implemented by Municipal
}

Environment Secretariats in the southeast region of Pará

Panorama de Políticas Públicas enfocadas en temas socioambientales implementadas por

Secretarías Municipales de Ambiente en la región sureste de Pará

Recebido: 28/02/2021 | Revisado: 06/03/2021 | Aceito: 02/05/2021 | Publicado: 16/05/2021

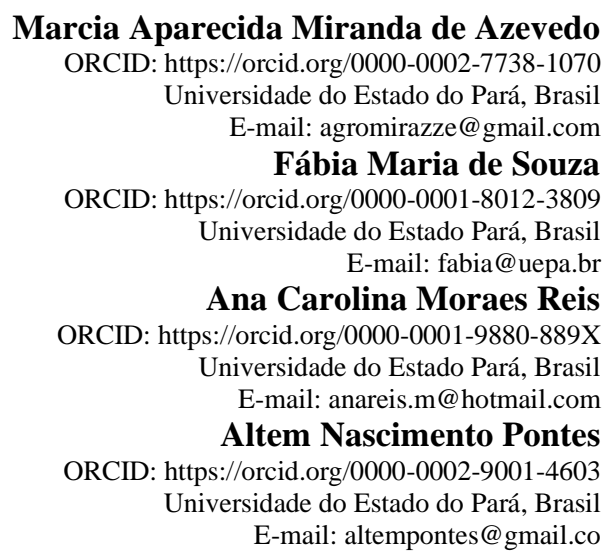

\begin{abstract}
Resumo
O objetivo deste estudo foi analisar os desafios que os municípios da microrregião de Paragominas, região sudeste do Pará, estão enfrentando ao implantar políticas públicas relacionadas às questões socioambientais, buscando compreender a dinâmica das Secretarias Municipais de Meio Ambiente. A pesquisa se baseia em abordagem qualiquantitativa, análise estatística e interpretação dos dados a partir da elaboração de figuras e tabelas no software Excel. Quanto aos resultados obtidos, nota-se que $100 \%$ dos municípios pesquisados implantaram a Política de Meio Ambiente e equipe técnica para licenciamento ambiental, importantes para a execução de políticas públicas, contudo, a implantação total de equipe técnica para fiscalização e implantação de tecnologia da informação não apresentaram unanimidade, apesar de serem importantes para garantir o cumprimento da legislação. Foi observado que $100 \%$ dos municípios aderiram ao Programa Municípios Verdes. Em relação às principais fontes de receitas, $100 \%$ dos municípios implantaram o Fundo Municipal de Meio Ambiente e também gestam sobre ele, no entanto, o ICMS Verde não apresenta unanimidade, na implantação da Lei, bem como da gestão de seus recursos, embora este seja uma importante fonte de receita. As principais políticas públicas desenvolvidas foram a implantação de aterros sanitários e ações de recuperação de áreas degradadas. As principais atividades licenciadas foram a agricultura e a pecuária, indicando interesse dos produtores pela legalidade. As principais ações de educação ambiental foram as palestras. Embora as secretarias municipais que compõem a microrregião estudada enfrentem desafios e limitações para a efetiva implantação de políticas públicas, percebe-se o esforço em promover a melhoria ambiental.
\end{abstract}

Palavras-chave: Gestão ambiental; Desenvolvimento urbano; Municipalização.

\begin{abstract}
The objective of this study was to analyze the challenges that the municipalities of the micro region of Paragominas, in the southeastern region of Pará, are facing when implementing public policies related to socio-environmental issues, seeking to understand the dynamics of the Municipal Secretariats of Environment. The research is based on a qualitative and quantitative approach, statistical analysis and data interpretation based on the elaboration of figures and tables in Excel software. Regarding the results obtained, it is noted that $100 \%$ of the surveyed municipalities implemented the Environmental Policy and technical team for environmental licensing, which are important for the implementation of public policies, however, the total implementation of the technical team for inspection and implementation of information did not show unanimity, although they are important to ensure compliance with the legislation. It was observed that $100 \%$ of the municipalities joined the Green Municipalities Program. Regarding the main sources of revenue, $100 \%$ of the municipalities have implemented the Municipal Environment Fund and also
\end{abstract}


manage it, however, the Green ICMS is not unanimous in the implementation of the Law, as well as the management of its resources, although this be an important source of revenue. The main public policies developed were the implementation of landfills and actions to recover degraded areas. The main licensed activities were agriculture and livestock, indicating producers' interest in legality. The main actions of environmental education were the lectures. Although the municipal secretariats that make up the studied micro-region face challenges and limitations for the effective implementation of public policies, there is an effort to promote environmental improvement.

Keywords: Environmental management; Urban development; Municipalization.

\section{Resumen}

El objetivo de este estudio fue analizar los desafíos que enfrentan los municipios de la micro región de Paragominas, en la región sureste de Pará, a la hora de implementar políticas públicas relacionadas con temas socioambientales, buscando comprender la dinámica de las Secretarías Municipales de Ambiente. La investigación se basa en un enfoque cualitativo y cuantitativo, análisis estadístico e interpretación de datos a partir de la elaboración de figuras y tablas en software Excel. En cuanto a los resultados obtenidos, se destaca que el $100 \%$ de los municipios encuestados implementó la Política Ambiental y el equipo técnico de licenciamiento ambiental, los cuales son importantes para la implementación de las políticas públicas, sin embargo, la implementación total del equipo técnico de inspección e implementación de información no mostró unanimidad, aunque son importantes para asegurar el cumplimiento de la legislación. Se observó que el 100\% de los municipios se adhirieron al Programa de Municipios Verdes. En cuanto a las principales fuentes de ingresos, el $100 \%$ de los municipios han implementado el Fondo Municipal de Ambiente y también lo administran, sin embargo, el ICMS Verde no es unánime en la implementación de la Ley, así como en el manejo de sus recursos, aunque este sea una importante fuente de ingresos. Las principales políticas públicas desarrolladas fueron la implementación de rellenos sanitarios y acciones de recuperación de áreas degradadas. Las principales actividades autorizadas fueron la agricultura y la ganadería, lo que indica el interés de los productores por la legalidad. Las principales acciones de educación ambiental fueron charlas. Si bien las secretarías municipales que integran la microrregión estudiada enfrentan desafíos y limitaciones para la implementación efectiva de las políticas públicas, existe un esfuerzo para promover el mejoramiento ambiental.

Palabras clave: Gestión ambiental; Desarrollo urbano; Municipalización.

\section{Introdução}

Quando não há um ambiente favorável ao desenvolvimento humano, no que tange à qualidade de vida, o bem-estar e a saúde, não existe também a dignidade humana, neste contexto, faz-se obrigatória a existência e a manutenção de um meio ambiente equilibrado e seguro (Machado \& Resende, 2019). Desse modo, Santos, et al. (2016) sugerem a execução de políticas públicas como maneira de garantir melhores condições socioambientais. Silva $(2019$, p. 5) define que [...] "as políticas públicas resultam da disputa entre interesses e ideias de atores estatais e não estatais por meio de negociação, barganha ou deliberação em canais formais e informais de interlocução".

Reis e Venâncio (2016) observam que para a eficácia de uma gestão adequada do meio social, o poder público deve planejar suas ações, sendo notório o dever de ser participativo, de modo que as políticas públicas estejam sempre direcionadas aos anseios sociais. Corroborando com essa afirmação, Leite, et al. (2020) destacam que quando as políticas públicas são executadas considerando os grupos sociais, bem como a diversidade das atividades econômicas, são mais eficazes e justas na distribuição tanto de esforço quanto de recursos. Oliveira e Galvão Jr. (2016) alertam para que as prestações dos serviços públicos estejam em concordância aos princípios gerais da administração pública previstos no Art. 37 da Constituição Federal.

Martins e Cândido (2015) explicam que é comum o poder público não conseguir atender a demanda da população em relação à infraestrutura e aos serviços urbanos quando as cidades surgem e crescem de forma desordenada ou com formas de planejamento ineficientes, ocasionando diversos problemas sociais, ambientais, econômicos e políticos. Desse modo, Smith, Mota Jr. e Castellari (2016) apontam para a grande responsabilidade que os munícipios possuem sobre a conservação da biodiversidade, de modo que os autores listam alguns aspectos que devem ser priorizados para a sua efetiva participação no processo, como por exemplo: a existência das Secretarias Municipais de Meio Ambiente; a implantação de políticas públicas de proteção da biodiversidade e ações de educação ambiental.

"A política ambiental é reconhecida por um conjunto de legislações, instituições e recursos que o poder público mobiliza para reduzir os conflitos e cumprir sua responsabilidade" (Borinelli, et al., 2019, p. 10). Desse modo, é importante 
observar a Lei 6.938/1981 que dispõe sobre a Política Nacional do Meio Ambiente, seus fins e mecanismos de formulação e aplicação, que tem por objetivo a preservação, melhoria e recuperação da qualidade ambiental propícia à vida (Brasil, 1981). Contudo, Valle (2018) comenta que em coerência com nossas legislações os gestores elaborem e executem políticas públicas considerando os orçamentos e as estimativas de despesas.

No estado do Pará, a política de Meio Ambiente é regida pela Lei ordinária n ${ }^{\circ} 5.887 / 1995$, na qual, em seu Art. $1^{\circ}$, define a Política Estadual do Meio Ambiente como "o conjunto de princípios, objetivos, instrumentos de ação, medidas e diretrizes, para o fim de preservar, conservar, proteger e defender o meio ambiente" (Pará, 1995). Ainda citando o referido artigo, o Parágrafo Único afirma que "as normas da Política Estadual do Meio Ambiente serão obrigatoriamente observadas na definição de qualquer política, programa ou projeto, público ou privado, no território do Estado” (Pará, 1995).

Assim sendo, um exemplo bem-sucedido de política pública no estado do Pará foi a criação do Programa Municípios Verdes (PMV), através do decreto $\mathrm{n}^{\circ}$ 54/2011, conforme especificado em seu artigo primeiro, no qual, "visa dinamizar a economia local em bases sustentáveis por meio de estímulos para que os municípios paraenses melhorem a governança pública municipal" (Pará, 2011). Tupiassu, Fadel e Désormeaux (2019, p.2) mencionam ainda outra política pública implantada no estado do Pará com o objetivo de favorecer a redução das altas taxas de desmatamento, que é o ICMS Verde, definido pelos autores como "apoio financeiro que consiste no dimensionamento, segundo critérios ambientais, de parte dos repasses da parcela do Imposto sobre Circulação de Mercadorias e Serviços que cabe aos municípios”.

Nunes, Philippi Jr e Fernandes (2012) relatam sobre a democratização e municipalização da gestão ambiental, que oportuniza os municípios a gestarem sobre os interesses locais e as peculiaridades ecológicas, econômicas e sociais de cada região em conformidade com a Lei Complementar 140/2011. Neste sentindo, o objetivo deste estudo foi analisar os desafios que os municípios da microrregião de Paragominas, região Sudeste do Pará, estão enfrentando ao implantar políticas públicas relacionadas às questões socioambientais, buscando através de pesquisa científica, obter subsídios para compreender a dinâmica das Secretarias Municipais de Meio Ambiente da microrregião estudada, contribuindo para o desenvolvimento sustentável local.

\subsection{Histórico de degradação ambiental}

A região pesquisada passou por várias fases de exploração ambiental nos últimos 60 anos, em virtude da história de integração da Amazônia nas décadas de 1960 e 1970, a princípio com a exploração da madeira e a implantação de pecuária nas áreas abertas pelas madeireiras. Nessa região, durante décadas a economia desses municípios era em razão das madeireiras e da pecuária (atividades que até hoje exercem papel fundamental na economia desses municípios).

No início dos anos 2000, apesar da elevada exploração das áreas para a retirada da madeira, surge uma nova atividade econômica rentável, a produção de carvão vegetal para abastecer as siderúrgicas das regiões vizinhas, promovendo a intensificação da devastação das áreas de floresta. Para efeito de comparação, de acordo com o relatório de acompanhamento de desmatamento do PMV, ano de 2008, apenas o munícipio de Rondon do Pará devastou $52 \mathrm{~km}^{2}$ de área de floresta. Concomitante a isso, as florestas em áreas de relevo plano também foram abertas para dar início à prática da agricultura em larga escala, com o plantio da soja e do milho. A devastação das florestas dessa região foi tão expressiva que a maioria desses municípios foram autuados na chamada operação "Arco de Fogo", desenvolvida no país inteiro em áreas de grandes desmatamentos e organizada pelo Ministério do Meio Ambiente, em conjunto com o IBAMA, Polícia Federal e Exército Brasileiro.

As consequências dessa operação impactaram diretamente na economia e geração de emprego dos municípios, uma vez que, as madeireiras foram fechadas; fornos de carvão destruídos; madeiras, máquinas e equipamentos apreendidos, com o 
consequente embargo das áreas e impedimento da execução de atividades econômicas, além da perda de benefícios de financiamentos de instituições financeiras.

A partir desse caos financeiro, os municípios foram forçados a se reestabelecerem, considerando que políticas públicas voltadas para questões socioambientais eram urgentes. O município de Paragominas lança o Programa Município Verde - PMV, que consiste em várias ações de regularização para se adequar ambientalmente e sair da condição de município embargado. O sucesso do Programa incentivou o Governo do Estado Pará a recriar o Programa em nível estadual e atualmente 132 municípios do Estado aderiram ao Programa, sendo que os municípios da microrregião de Paragominas, incluídos neste estudo, aderiram totalmente ao PMV. O processo consiste em promover o cumprimento das metas estabelecidas pelo PMV, com o objetivo de modificar o status de município embargado para o reconhecimento com o título de Município Verde. Atualmente, os municípios que já receberam esse título na microrregião deste estudo foram: Paragominas, Ulianópolis, Bom Jesus do Tocantins e Rondon do Pará.

Os municípios atendidos pelo PMV receberam vários incentivos para fortalecer a gestão ambiental local, como a aquisição de veículos para a realização de fiscalização e vistorias em decorrência do licenciamento ambiental. Foram beneficiados também com equipamentos como: computadores, impressoras, GPS, decibelímetros, binóculos e câmeras fotográficas, além da realização de diversos cursos de qualificação para os servidores das secretarias municipais de meio ambiente.

Outra política pública também implantada para promover a qualificação da Gestão Ambiental Municipal foi a criação do ICMS Verde, instituído pela Lei 7.638, de 12 de julho de 2012 e regulamentado pelo Decreto 775, de 26 de junho de 2013, na qual o repasse dos valores que são destinados aos municípios tem seus critérios e metodologias de partilha descritos na Portaria SEMAS 1.562/2013.

\section{Material e métodos}

\section{1 Área de estudo}

Segundo o IBGE (2019), o estado do Pará está dividido em seis mesorregiões. A área de estudo está situada na mesorregião sudeste paraense, a qual está dividida em sete microrregiões. Este estudo foi desenvolvido na microrregião de Paragominas, que é composta pelos seguintes munícipios: Paragominas, Ulianópolis, Dom Eliseu, Rondon do Pará, Abel Figueiredo, Bom Jesus do Tocantins e Goianésia do Pará (ver Figura 1). 
Figura 1 - Área de abrangência do experimento.

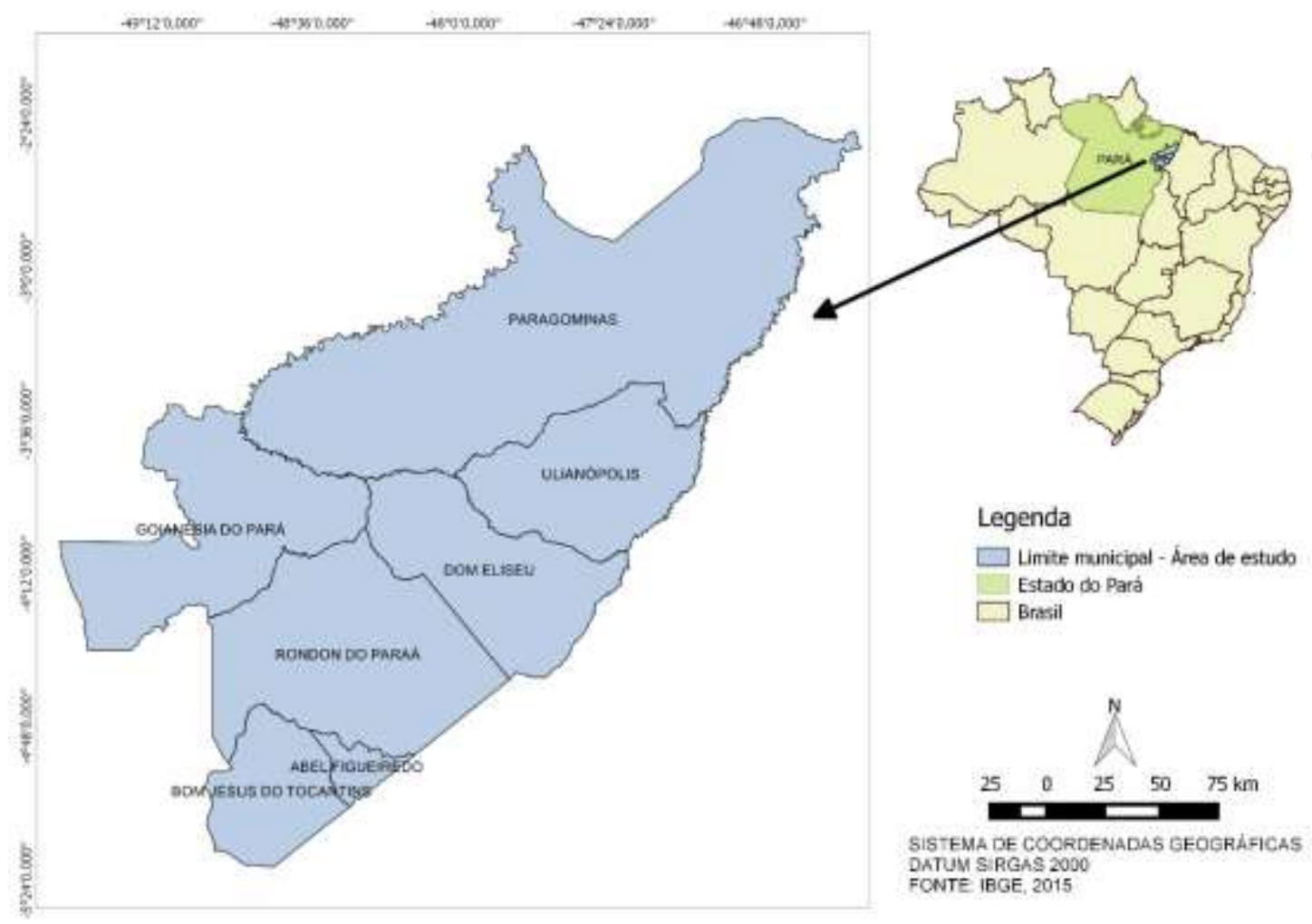

Fonte: Autores (2020).

\subsection{Tipo de pesquisa}

A pesquisa respalda-se na investigação das políticas públicas voltadas para questões socioambientais implantadas durante os anos 2017, 2018 e 2019 pelas Secretarias Municipais de Meio Ambiente dos municípios pertencentes à microrregião de Paragominas no sudeste paraense. Assim sendo, este estudo se baseia em uma abordagem de natureza qualitativa e quantitativa, sendo que os métodos qualitativos são aqueles onde o pesquisador esclarece com suas convicções os efeitos do estudo, na qual a coleta de dados na maioria das vezes se realiza por meio de entrevistas com questões abertas, enquanto que nos métodos quantitativos se usam medições de grandezas, o que possibilita criar massa de dados que permitem a interpretação dos mesmos através de técnicas matemáticas, por exemplo, as porcentagens, também usadas nessa pesquisa (Pereira et al., 2018).

\subsection{Coleta de dados}

A coleta de dados se deu por meio de análise de documentos e legislação, aplicação de questionário, com perguntas objetivas e subjetivas, aos secretários de Meio Ambiente dos municípios pesquisados e visita in loco para se verificar as respostas necessárias para elaboração de questionário a fim de construir o panorama de políticas públicas, objeto desse estudo.

O campo da pesquisa compreende seis dos sete municípios que compõem a referida microrregião, correspondendo assim a 85,7\% do universo amostral, porque a secretaria de Meio Ambiente do município de Goianésia do Pará não retornou o questionário. A coleta de dados foi realizada nos meses de fevereiro e março de 2020.

\subsection{Análise de dados}

A análise de dados foi baseada em estatística descritiva, para obtenção de médias e frequências e posterior elaboração 
de tabelas e figuras.

\section{Resultados}

A partir dos resultados obtidos através da apuração de seis questionários, aplicados nas secretarias municipais de Meio Ambiente dos municípios que compõem a microrregião de Paragominas, com exceção do município de Goianésia do Pará, que não participou da pesquisa, foi possível realizar uma análise das estruturas das referidas secretarias.

Em relação aos percentuais dos municípios pesquisados, no que tange às condições de oferta de serviços básicos à população, nota-se que 100\% dos municípios pesquisados implantaram a Política de Meio Ambiente que é o primeiro passo para a regulamentação e o planejamento para a execução de políticas públicas voltadas para questões socioambientais, assim como todas as secretarias também implantaram equipe técnica para o licenciamento ambiental. Contudo, não houve unanimidade entre os municípios na implantação total de equipe técnica para fiscalização, correspondendo a $66,7 \%$ dos municípios neste quesito. A implantação de tecnologia da informação também não apresentou unanimidade nos municípios pesquisados, a qual consta como totalmente implantada em 83,3\% dos municípios (Figura 2).

Figura 2 - Análise das estruturas das secretarias municipais para a prestação de serviços básicos.

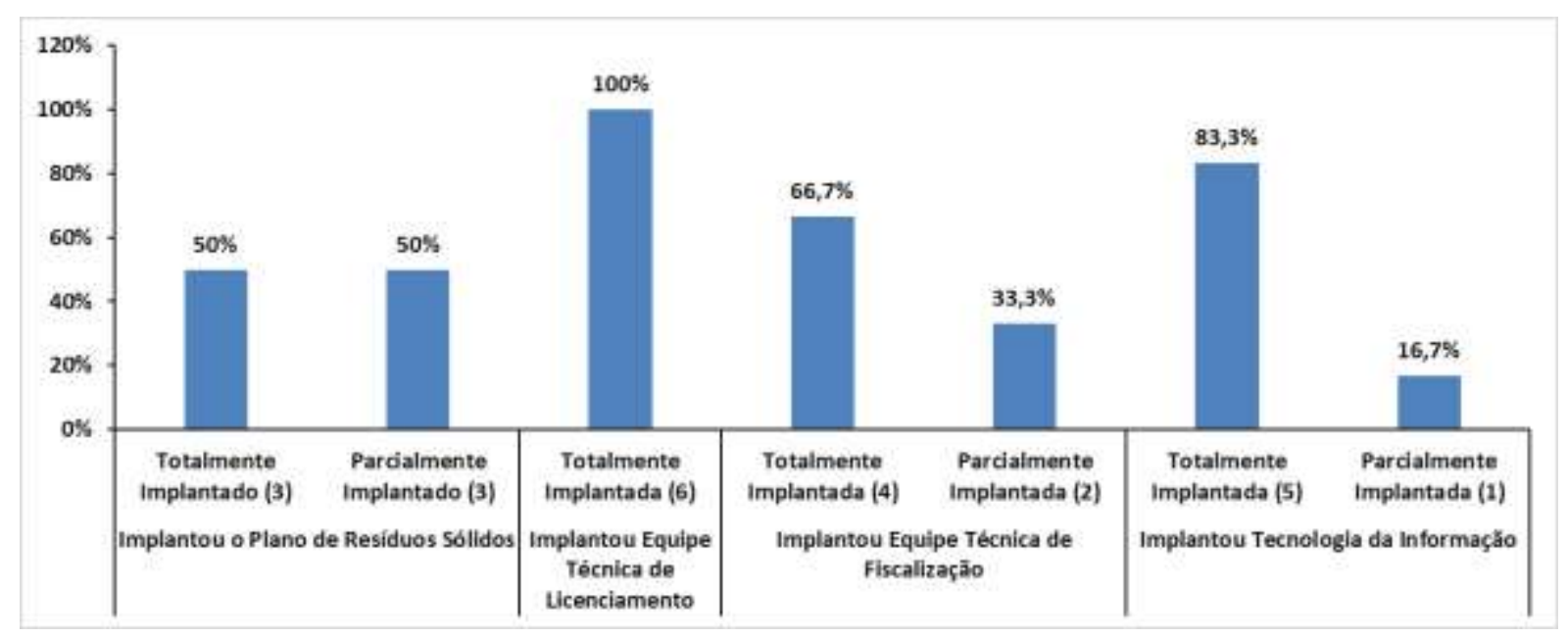

Fonte: Pesquisa de campo (2020).

Ao observar as principais fontes de receitas, arrecadações e aquisições de bens das secretarias municipais da microrregião estudada, verificou-se que 100\% dos municípios aderiram ao PMV, e foram beneficiados com aquisição de veículos, máquinas e equipamentos que auxiliam na gestão ambiental. Também foi constatado que $100 \%$ dos municípios implantaram o Fundo Municipal de Meio Ambiente para arrecadação de receitas de multas, taxas de licenciamento e prestação de serviços. No entanto, o ICMS Verde não apresenta unanimidade nos municípios, podendo ser observado que apenas $66,7 \%$ destes implantaram a Lei municipal que regulamenta o referido repasse (Figura 3). 
Figura 3 - Análise das fontes de receitas, arrecadações e aquisição de bens das secretarias municipais.

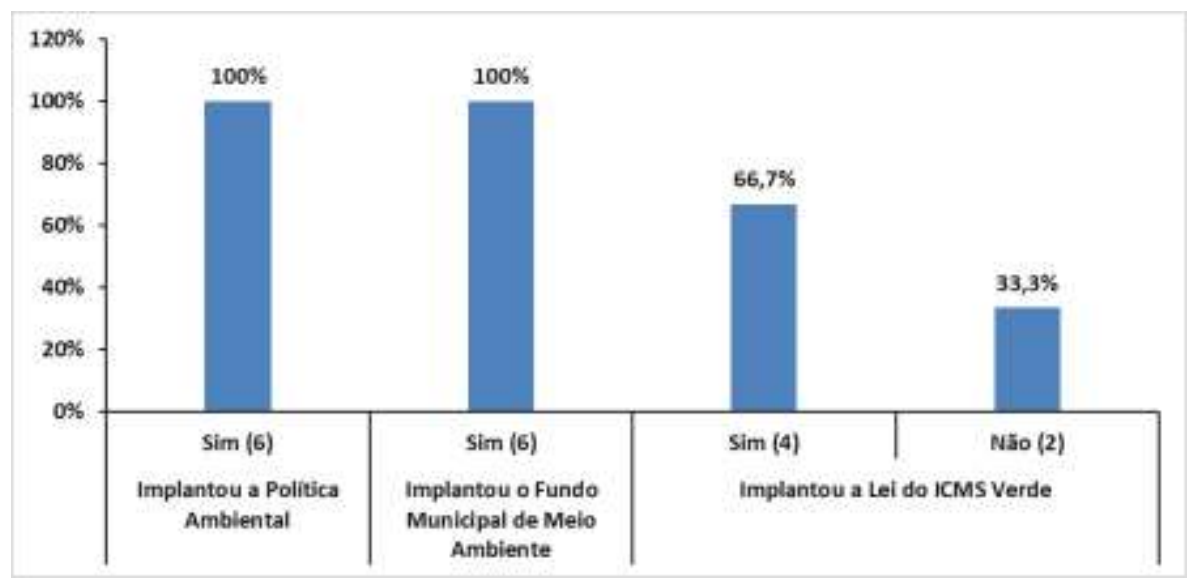

Fonte: Pesquisa de campo (2020).

Em relação à autonomia que as secretarias municipais de meio ambiente possuem em gerir seus próprios recursos, observa-se que $100 \%$ gestam sobre os recursos provenientes do Fundo Municipal de Meio Ambiente. No entanto, no que se refere aos recursos advindos do ICMS Verde, 66,7\% dos municípios instituíram a Lei que regulamenta o repasse, enquanto os municípios que não implantaram a Lei correspondem a 33,3\% deles (Figura 4).

Figura 4 - Análise da gestão dos recursos financeiros pelas secretarias municipais.

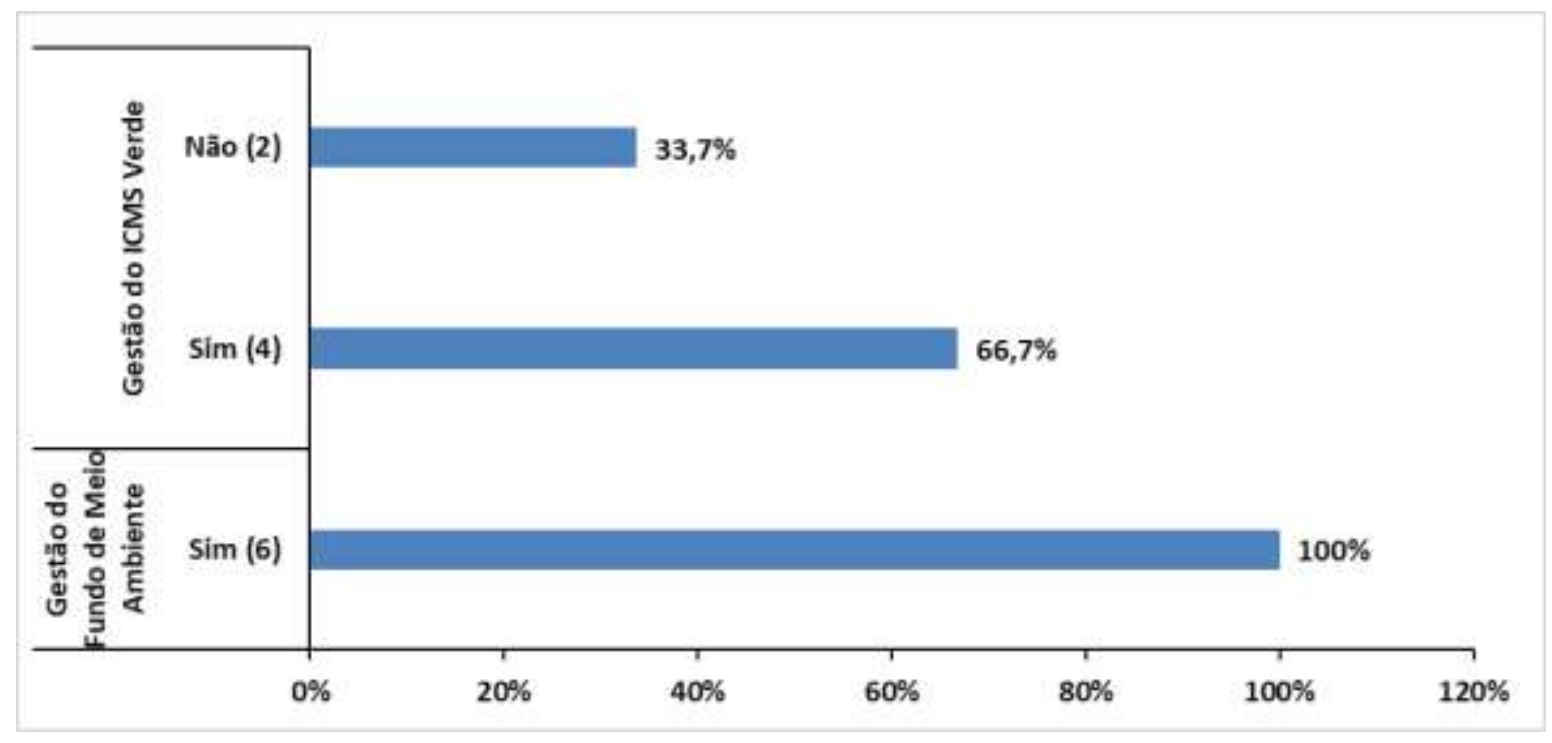

Fonte: Pesquisa de campo (2020).

Ao elencar as principais políticas públicas que foram implantadas pelas secretarias municipais de meio ambiente nos últimos três anos, nota-se o destaque para a implantação de aterros sanitários e ações de recuperação de áreas degradadas (Tabela 1). 
Research, Society and Development, v. 10, n. 5, e54610513406, 2021

(CC BY 4.0) | ISSN 2525-3409 | DOI: http://dx.doi.org/10.33448/rsd-v10i5.13406

Tabela 1 - As principais políticas públicas implantadas pelas secretarias municipais.

\begin{tabular}{l|c}
\hline \multicolumn{1}{c|}{ Políticas Públicas } & Número de Municípios \\
\hline Construção de Aterro Sanitário & 3 \\
\hline Recuperação de Áreas Degradadas & 3 \\
\hline Plano Municipal de Gestão Integrada de Resíduos Sólidos & 2 \\
\hline Análise e Validação do CAR & 2 \\
\hline Política de Logística Reversa & 2 \\
\hline Monitoramento de Áreas de Proteção Ambiental & 2 \\
\hline Projetos de Educação Ambiental & 2 \\
\hline Recuperação de Nascentes & 1 \\
\hline Criação de Parque Ambiental & 1 \\
\hline Controle de Barragens de Água & 1 \\
\hline
\end{tabular}

Fonte: Pesquisa de campo (2020).

Em relação as principais atividades licenciadas pelas secretarias municipais de meio ambiente nos últimos três anos, atenta-se para as atividades de agricultura e pecuária, enfatizando o potencial produtivo da região (Tabela 2).

Tabela 2 - As principais atividades licenciadas pelas secretarias municipais.

\begin{tabular}{l|c}
\multicolumn{1}{c|}{ Atividades para Licenciamento } & Número de Municípios \\
\hline Agricultura & 6 \\
\hline Pecuária & 5 \\
\hline Posto de Combustível & 5 \\
\hline Extração de Areia e Seixo & 5 \\
\hline Reflorestamento & 4 \\
\hline Serraria & 3 \\
\hline Laticínio & 3 \\
\hline Supermercado & 3 \\
\hline Oficina Mecânica & 2 \\
\hline Depósito de Gás & 8 \\
\hline Outros & 6 \\
\hline
\end{tabular}

Fonte: Pesquisa de campo (2020).

Ao abordar aspectos relacionados à educação ambiental e as principais ações promovidas pelas secretarias municipais de meio ambiente, pode-se observar que a exposição oral da temática em formato de palestra é a metodologia mais utilizada, tendo as escolas como o maior público-alvo (Figura 5). 
Figura 5 - Análise das ações de educação ambiental promovida pelas secretarias municipais.

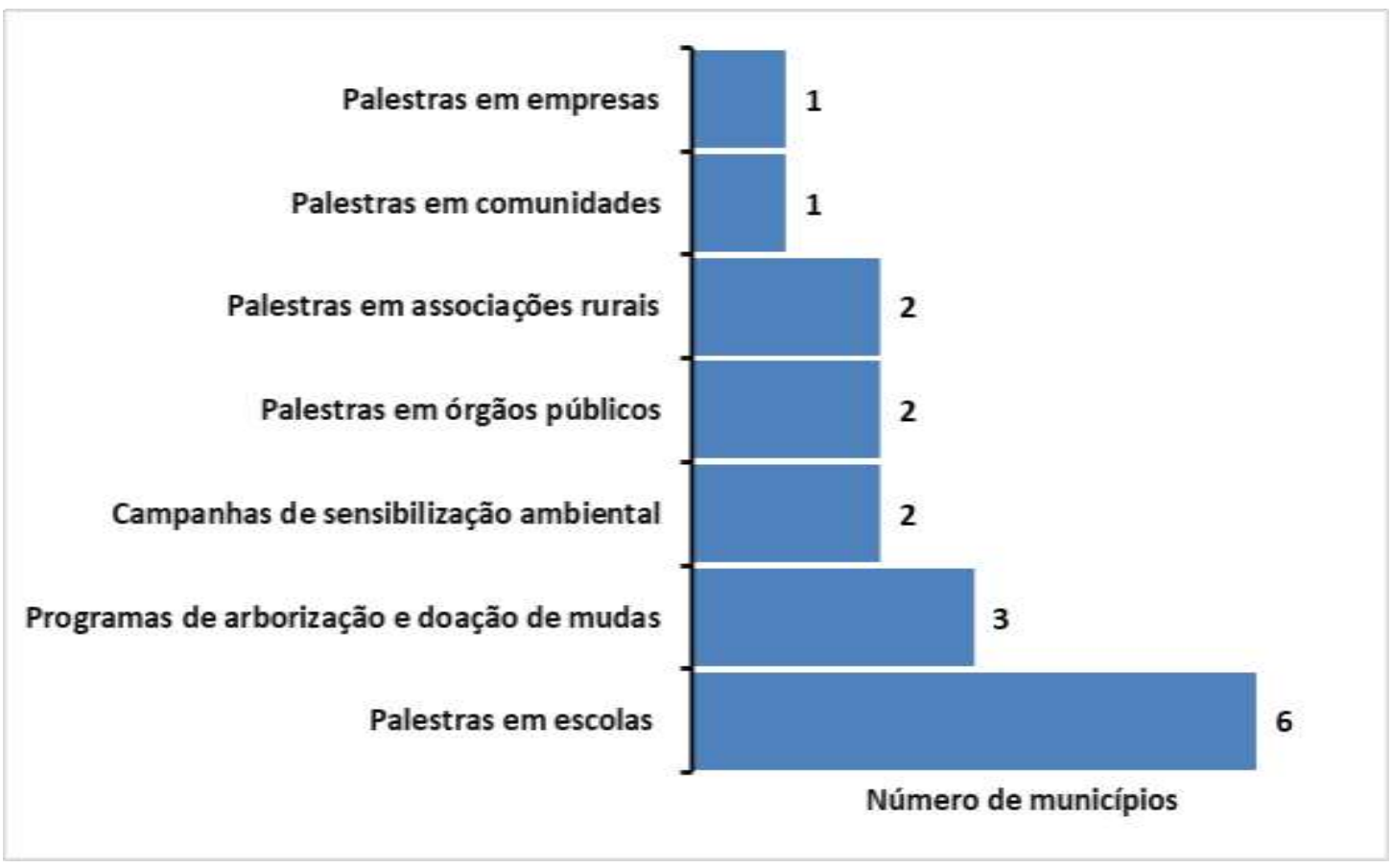

Fonte: Pesquisa de campo (2020).

\section{Discussão}

Diante do exposto, foi possível observar que os municípios da microrregião de Paragominas implantaram a Política Municipal de Meio Ambiente dando início à regulamentação. Este processo é primordial para o planejamento e execução de políticas públicas voltadas para questões socioambientais, uma vez que, a Lei 6.938/1981, abarca os municípios no Sistema Nacional do Meio Ambiente (SISNAMA) (Brasil, 1981). A implantação de equipe técnica para o licenciamento ambiental, realizada pelas secretarias municipais, é relevante ao considerar que o licenciamento favorece a legalização ambiental dos empreendimentos que geram emprego e renda aos municípios

Considerando a observação de que em parte dos municípios da microrregião estudada a equipe para a fiscalização não está totalmente implantada, deve-se destacar que o setor de fiscalização é imprescindível para garantir o cumprimento da legislação e o gerenciamento dos resíduos e rejeitos no funcionamento dos empreendimentos. Em debates sobre a fiscalização ambiental há várias discussões sobre as limitações em fazê-la, pois não há garantia de segurança para os agentes da fiscalização, que muitas vezes recorrem ao apoio da Polícia Militar. Em relação ao outro quesito relevante, o qual foi observado que não houve implantação total de Tecnologia da Informação em parte dos municípios, embora identificado em menor percentual, também é considerado imprescindível para o monitoramento e fiscalização, especialmente no que tange às ações de combate e controle do desmatamento, pois, de acordo com Gama, et al. (2021), as técnicas de sensoriamento remoto e geoprocessamento permitem visualizar e constatar modificações na cobertura do solo, contribuindo nas deliberações dos órgãos competentes de fiscalização.

Quanto aos recursos adquiridos para custear as demandas e fomentar as ações das secretarias municipais de meio ambiente, embora todas as secretarias dos municípios pesquisados tenham aderido ao PMV e, consequentemente, tenham recebido subsídios em materiais, veículos e equipamentos que certamente contribuem para a gestão ambiental municipal, foi possível perceber que o ICMS Verde, que é de uma das maiores fontes de receita destinada às prefeituras, o qual deve ser repassada às secretarias de meio ambiente por meio de lei municipal específica, nem sempre é repassado de forma integral às secretarias municipais de meio ambiente ou em alguns casos, não há repasse algum. A importância do repasse do ICMS Verde 
dá-se em função de sua perspectiva de trabalho que visa o combate ao desmatamento, a regularização ambiental por meio do Cadastro Ambiental Rural (CAR), bem como a economia rural sustentável (Outeiro, 2019).

Em relação à autonomia para a gestão dos recursos advindos do ICMS Verde, a maioria dos municípios instituíram a Lei que regulamenta o referido repasse, sendo que nos casos em que o município não implantou, por obvio, não há autonomia de gestão sobre esse recurso. Sobre a autonomia de gestão das secretarias municipais de meio ambiente aos recursos provenientes do Fundo Municipal de Meio Ambiente, todas as secretarias possuem liberdade para utilizá-lo, contudo, é importante destacar que esses valores são relativamente diminutos em municípios menores, uma vez que, são mínimas as arrecadações em taxas de licenciamentos, prestações de serviços e/ou multas aplicadas, sendo necessário o investimento de maiores recursos para atender as demandas. Neste contexto, Pinto, et al. (2018) ressaltam a importância da autonomia das secretarias municipais sobre recursos financeiros, bem como autonomia política, pois no caso contrário, a tarefa de governar torna-se limitada.

Quanto às principais políticas públicas implantadas pelas secretarias municipais, os grandes destaques foram a implantação de aterros sanitários e a recuperação de áreas degradadas. No que se refere à criação de aterros sanitários, considerando os graves problemas ambientais causados pela destinação inadequada de resíduos sólidos, a implantação destes é uma obrigatoriedade instituída na Lei 12.305/2010 que trata a Política Nacional de Resíduos Sólidos (Brasil, 2010). Ponderando os benefícios ambientais associados à implementação de práticas para a recuperação de áreas degradadas, estas também se destacaram como ações de políticas públicas desenvolvidas pelas secretarias municipais de meio ambiente.

As atividades de agricultura e pecuária são as principais atividades licenciadas pelas secretarias municipais, indicando o interesse dos produtores em buscar legalidade e segurança jurídica para comercialização da produção, bem como para receber fomentos e incentivos das instituições financeiras.

Em relação à educação ambiental, o enfoque maior para as palestras em escolas, corrobora com as colocações de Pita, et al. (2021, p. 7) quando os autores reforçam que "a educação ambiental, em suas inúmeras possibilidades, abre um grande espaço para pensar e executar práticas sociais". Por isso, os Parâmetros Curriculares Nacionais recomendam tratar o meio ambiente como tema transversal, no qual pode ser abordado de forma interdisciplinar, sugerindo que a educação ambiental pode ser um elemento transformador através do conhecimento e da sensibilização da comunidade escolar (Brasil, 1998).

\section{Considerações Finais}

Considerando a urgência de ações a serem desenvolvidas e regulamentadas e, principalmente, tendo em vista a constante degradação do meio natural, com consequências maléficas ao meio ambiente e à qualidade de vida das pessoas, é fundamental que poder público desenvolva políticas públicas eficazes para o equilíbrio ecológico local.

É importante destacar a relevância do fortalecimento da gestão ambiental municipal, através da legitimação dos atos normativos, estruturação das secretarias municipais de meio ambiente e a regulamentação das formas de captação de recursos com autonomia na gestão e aplicação destes para prestação de serviços ambientais. Embora, as secretarias municipais dos municípios que compõem a microrregião de Paragominas enfrentem desafios e limitações para a efetiva implantação de políticas públicas voltadas para questões ambientais, percebe-se o esforço em promover a melhoria ambiental e, consequentemente, a qualidade de vida da população.

Diante do contexto apresentado, para direcionar estudos futuros acerca da execução de políticas públicas socioambientais implantadas por secretarias de meio ambiente dos municípios do sudeste paraense, sugere-se expandir o banco de informações a partir da aplicação dos instrumentos de coleta de dados em outros órgãos e instituições que também desenvolvam políticas socioambientais na microrregião pesquisada, a fim de atualizar e difundir o conhecimento científico sobre a região. 


\section{Referências}

Borinelli, B., Gallassi, J., Mostagi, N., Almeida, D \& Costa, R. (2019). (Des)ordem institucional e ordenamento territorial: considerações sobre a política ambiental de Goiás. Revista de Geografia e Ordenamento do Território (GOT), (16), 5-27.

Brasil. (1981). Lei n 6.938 de 31 de agosto de 1981. Dispõe sobre a Política Nacional do Meio Ambiente, seus fins e mecanismos de formulação e aplicação, e dá outras providências. Diário Oficial da União.

Brasil. (2010). Lei n 12.305 de 02 de agosto de 2010. Institui a Política Nacional de Resíduos Sólidos. Diário Oficial da União.

Brasil. (1998). Parâmetros Curriculares Nacionais: terceiro e quarto ciclos do Ensino Fundamental: temas transversais. MEC/SEF.

Gama, L. H. O. M., Paiva, P. F. P. R., Silva Jr., O. M. \& Ruivo, M. L. P. (2021). Modelagem ambiental e uso da inteligência artificial para prognóstico de desmatamento: o caso da Rebio do Gurupi-MA. Research, Society and Development, 10 (2).

Leite, M. de S, Silva Jr., J. A. da, Calaboni, A. \& Igari, A. T. (2020). Fatores socioeconômicos e capa de vegetação nativa em terrenos rurais do estado de São Paulo, Brasil. Ambiente \& Sociedade. São Paulo, 23

Machado, C. A. A. \& Resende, A. C. L. De. (2019). Tecnologia, meio ambiente e democracia: reflexões necessárias. Revista de Investigações Constitucionais. 6 (3), 749-771.

Martins, M. de F. \& Cândido, G. A. (2015). Modelo de avaliação do nível de sustentabilidade urbana: proposta para as cidades brasileiras. Revista Brasileira de Gestão Urbana, 7 (3), 397-410.

Nunes, M. R., Philippi Jr., A. \& Fernandes, V. (2012). A atuação de conselhos do meio ambiente na gestão ambiental local. Saúde e Sociedade, 21 (3), 48-60.

Oliveira, T. B. \& Galvão Jr., A. C. (2016). Planejamento municipal na gestão dos resíduos sólidos urbanos e na organização da coleta seletiva. Revista Engenharia Sanitária e Ambiental, 21 (1), 55-64.

Outeiro, G. M. (2019). ICMS Verde e Sustentabilidade Ambiental: Um estudo em 5 municípios do sul e sudeste do Pará. Revista de Finanças Públicas, Tributação e Desenvolvimento, 7 (9).

Pará. (2011). Decreto n 54 de 29 de março de 2011. Institui o Programa Municípios Verdes. Diário Oficial do Estado.

Pará. (2013). Decreto n 775 de 26 de junho de 2013. Regulamenta o critério ecológico para crédito das parcelas de receita de que trata a Lei no 7.638 , de 12 de julho de 2012. Diário Oficial do Estado.

Pará. (1995). Lei n 5.887 de 09 de maio de 1995. Da Política Estadual de Meio Ambiente. Diário Oficial do Estado.

Pará. (2012). Lei n 7.638 de 12 de julho de 2012. Dispõe sobre o tratamento especial de que trata o $§ 2^{\circ}$ do art. 225 da Constituição do Estado do Pará. Diário Oficial do Estado.

Pereira, A. S., Shitsuka, D. M., Parreira, F. J. \& Shitsuka, R. (2018). Metodologia da Pesquisa Científica. UFSM

Pinto, T. R. G. S., Martins, S., Leonel, D. S. \& Ckagnazaroff, I. B. (2018). Governança Participativa: possibilidades e desafios na gestão local. Interações, 19 (3), 627-641.

Pita, J. D., Pinheiro, K. A. O., Carneiro, F. da S., D’Arace, L. M. B., Lima, A. C. R. de \& Frazão, A. da S. (2021). Educação Ambiental no currículo técnico profissionalizante: Uma ferramenta para valorizar o meio ambiente e promover a consciência do aluno sobre a situação do planeta. Research, Society and Development, $10(2)$.

Reis, E. V. B. \& Venâncio, S. R. (2017). O direito à cidade e a participação popular no planejamento urbano municipal. Revista Direito e Desenvolvimento, 7 (2), 222-247.

Santos, D. A. S., Azevedo, P. V., Azevedo, J. V. V., Bezerra A. T. L. \& Souza, A. (2016). Percorrendo os caminhos da relação entre as políticas públicas de saúde e do meio ambiente. Revista de Políticas Públicas, 20 (1), 137-152.

Silva, V. P. (2019). Alguns Condicionantes da Capacidade de Influência das Conferências de Políticas Públicas sobre os Programas das Respectivas Políticas Setoriais. Dados, $62(1)$.

Smith, W. S., Mota Jr., V. D. \& Castellari R. R. (2016). O papel do município na conservação da biodiversidade. Revista de Biologia Neotropical, 13 (2), 285299.

Tupiassu, L., fadel, L. P. S. L. \& Gros-Désormeaux, J. R. (2019). ICMS Ecológico e desmatamento nos municípios prioritários do Estado do Pará. Revista Direito $G V, 15$ (3).

Valle, V. L. (2018). Planejamento orçamentário e políticas públicas: explorando uma alternativa de reconciliação pela indução. Revista de Investigações Constitucionais, 5 (2), 113-134. 